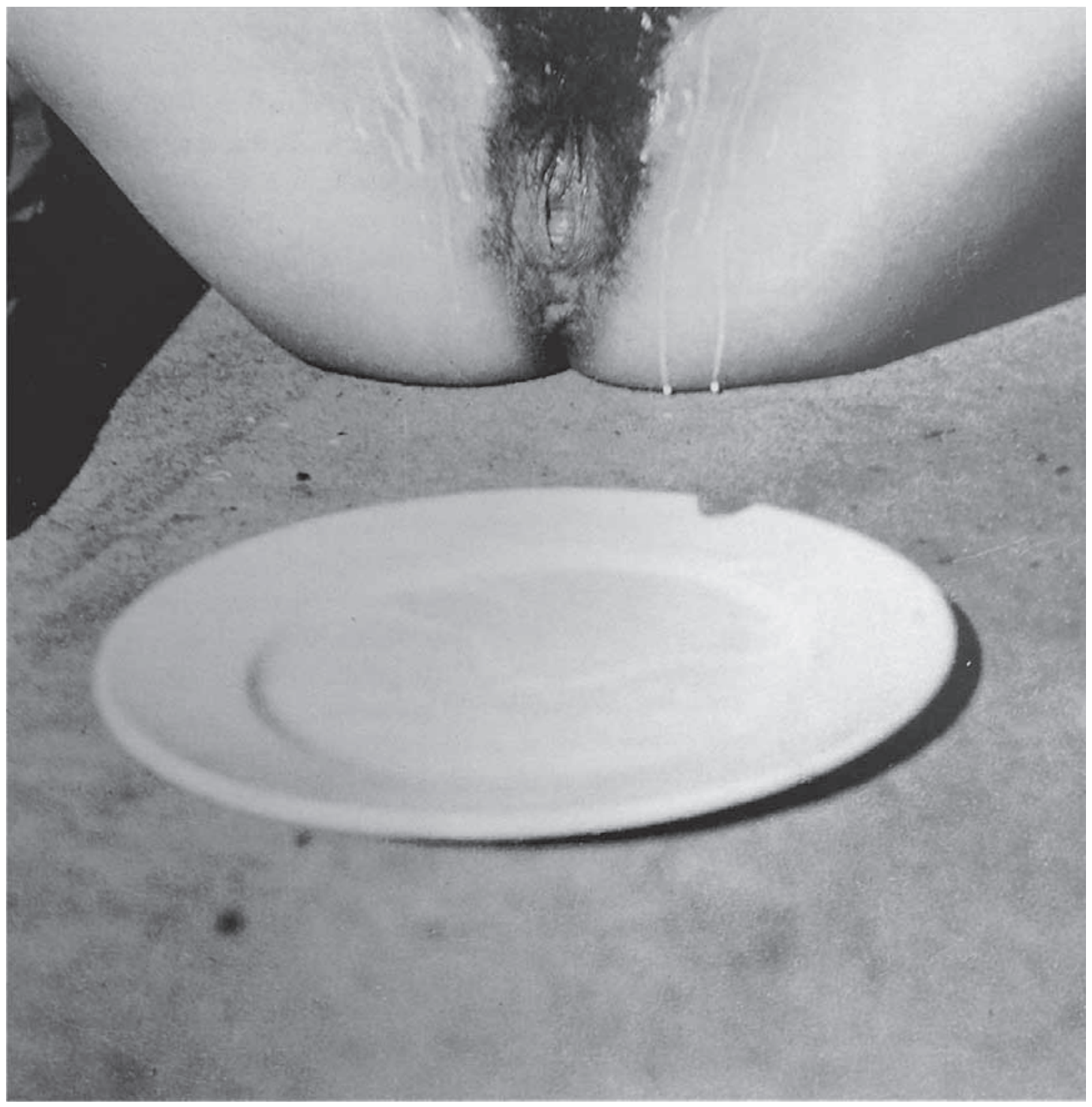


ARS Regilene Sarzi Ribeiro*

ano 12

n. 23 Diálogos estéticos e alguns caminhos da intertextualidade para a história da arte e do vídeo".

palavras-chave: intertextualidade; videoarte; história da arte; arte brasileira contemporânea. intertextuality; video art; art history; contemporary Brazilian art.

Hans Bellmer, 1946

* Universidade Estadual Paulista [UNESP Bauru].
Trata-se de um exercício sobre a intertextualidade em quatro videoartes brasileiras produzidas entre os anos de 1975 e 2002. A abordagem metodológica é pautada na descrição de intertextos e percursos iconográficos que podem levar o crítico de arte e o público ao texto audiovisual. Os diálogos estéticos revelam diferentes referências intertextuais e elementos plásticos que formam uma rede de relações iconográficas. A partir da análise estética, são tecidas relações entre vídeos e obras de arte de diferentes épocas, visando narrar uma breve história da arte por meio da intertextualidade.

This is an exercise in intertextuality in four Brazilian video art works produced between 1975 and 2002. The methodological approach is based on the description of intertextual and iconographical pathways that can lead the art critic and the public to the audiovisual text. The aesthetic dialogues reveal different intertextual references and plastics elements that form a network of iconographic relations. From the aesthetic analyses, relationships between videos and artworks from different periods are woven in order to tell a brief history of art through intertextuality. 


\section{REGILENE RIBEIRO}

Diálogos estéticos e

alguns caminhos da

intertextualidade para

história da arte e do vídeo

1. Este artigo apresenta um dos aspectos analisados em cada uma das quatro videoartes que integraram o corpus da minha Pesquisa de Doutorado, defendida em 2012, junto ao Programa de Estudos Pós-Graduados em Comunicação e Semiótica da Pontifícia Universidade Católica de São Paulo.

2. FERreirA, A. B. de H. Novo dicionário eletrônico Aurélio. Versão 7.0. 5a. Edição do Dicionário Aurélio de Língua Portuguesa. São Paulo: Ed. Positivo, 2010.

3. FIORIN, J. L. Polifonia textual e discursiva. In: BARROS, D. L. P. de; FIORIN, J. L. (org.). Dialogismo, polifonia, intertextualidade

4. Ver os comentários de Calabrese sobre o conceito de intertextualidade de Gérard Genette e a "[...] tipologia que ele propõe chamar de transtextualidade que compreende cinco diferentes manifestações" CALABRESE, 0 . A intertextualidade na pintura. Uma leitura de Os embaixadores de Holbein. In: OLIVEIRA, Ana Claudia de (org.). Semiótica Plástica. rama da arte contemporânea por meio da intertextualidade (citações, alusões, indicações iconográficas), tomando como referência um conjunto de videoartes brasileiras.

Não se trata de afirmar que o artista que produziu determinada videoarte cita, menciona, alude ou se refere diretamente a esta ou
5. Idem, Ibidem, p. 162. 

linguagens, meios e intertextos. Considerando, sobretudo, que esses intertextos podem configurar ainda diferentes caminhos para levar o crítico de arte e o público ao texto audiovisual.

Os quatro vídeos que compõem os objetos de estudo deste breve ensaio sobre a intertextualidade videográfica na história da arte contemporânea fazem parte de um conjunto de obras audiovisuais produzidas entre os anos 1970 e 2002: Marca Registrada (1975), de Letícia Parente, Entre (1999), de Nina Galanternick, Narciso (2000), de Danillo Barata e Desenho-corpo (2002), de Lia Chaia (Fig. 1 a 4).

\section{Diálogos estéticos, intertextos visuais}

O vídeo Marca Registrada, de Letícia Parente, é, como se sabe, uma das principais referências da primeira geração da produção videográfica brasileira. Ao passo que o vídeo Desenho-corpo, de Lia Chaia, e os demais trabalhos analisados participam de um grupo de vídeos produzidos recentemente no Brasil, a partir dos anos 1990 - época considerada pelos pesquisadores do audiovisual como o período de con-

7. MACHADO, A. (org.) Made in Brasil. Três décadas do vídeo brasileiro.

8. MELLO, C. Extremidades do vídeo. solidação da arte do vídeo no país ${ }^{7}$.

A aproximação de vídeos de épocas e gerações artísticas diferentes permite problematizar questões como o hibridismo na linguagem audiovisual com mais profundidade. Além disso, esses artistas abrigam em seus trabalhos um repertório de discursos sobre o corpo na contemporaneidade, a partir de discussões constantes sobre beleza, liberdade, identidade, comportamentos sociais, e também por meio da relação e do embate direto e frontal com a câmera e com a visualidade videográfica. Marca Registrada é descrito por Christine Mello como:

Um corpo feminino sentado num banco com as pernas cruzadas e um dos pés diante da câmera [...]. Nas mãos, agulha e linha preta. Com firmeza, a linha é passada pelo buraco da agulha e faz um nó em uma das pontas. A mão delicada deliberadamente inicia uma costura incomum. Aqui o suporte não é algodão ou linho, mas a própria pele da artista. Não há titubeios, são gestos precisos os de Letícia Parente em sua performance, em tempo real, diante de uma câmera de vídeo ${ }^{8}$. 
Diante das cenas de Marca Registrada, o público compartilha a experiência de bordar o próprio corpo, de costurar na sola do pé as palavras made in Brasil. Assim, a prática artística se transforma em prática vivencial, uma vez que a obra é participada e habitada ao mesmo tempo, no aqui e agora, por quem a fez (artista) e por quem a observa (público).

A partir dos anos 2000, mesmo tendo como cenário um contexto bem diferente dos anos 1970, ressurgem manifestações performáticas como aquelas observadas na primeira geração do audiovisual brasileiro, em que as intersecções entre arte e política eram o mote das práticas performáticas. O exercício de aproximação revela que a diferença entre os vídeos dos anos 1970 e os atuais está mesmo no contexto tecnológico. Muito embora, para muitos, o corpo continue sendo objeto de repressão, vigilância e poder, e a linguagem do vídeo, o campo de batalha no que diz respeito às relações entre homem, sociedade e meios de comunicação.

Nas produções atuais, o que se observa é que o vídeo passa a ser explorado de forma crítica, com a consciência da multiplicidade e dos desafios da linguagem, somada à resistência política que os pioneiros da videoarte tinham diante da mídia televisiva e do poder totalitarista do governo militar da época. São desta fase contemporânea, denominada pelos pesquisadores "terceira geração", os demais vídeos analisados: Entre, de Nina Galanternick; Narciso, de Danillo Barata e Desenho-corpo, de Lia Chaia. Para Arlindo Machado:

A terceira geração de videastas brasileiros não representa propriamente uma virada radical de estilo, forma e conteúdo em relação às outras duas fases já vividas pelo vídeo. Na verdade, essa nova geração, que desponta publicamente nos anos de 1990, tira proveito de toda a experiência acumulada, faz a síntese das outras duas gerações e parte para um trabalho mais maduro, de solidificação das conquistas anteriores ${ }^{9}$.

No vídeo Entre, imagens que investigam o corpo revelam diversos olhares que se podem ter sobre o corpo. A procura segue por outros objetos e materiais de desejo humano, que podem ou não ser adentrados, penetrados. O vídeo remete à reflexão sobre os mecanismos do desejo e os modos de experimentar o prazer. Danillo Barata, por sua vez,

\section{REGILENE RIBEIRO}

Diálogos estéticos e alguns caminhos da intertextualidade para história da arte e do vídeo

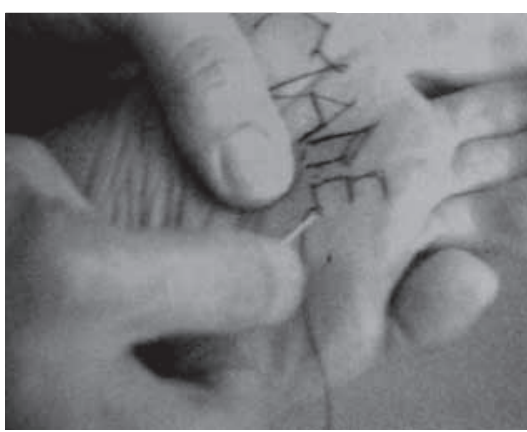

FIGURA 1. Letícia Parente.

Frame do vídeo Marca Registrada, 1975. 10'. Portapack (1/2 polegada, open reel Sonyl, P\&B.
9. MACHADO, A. Arte e Mídia. 
imagem eletrônica resultam em videoartes não mais produzidas apenas por meio de um dispositivo básico e um único plano contínuo, tomado em tempo real.

A imagem eletrônica trouxe ao campo das experimentações estéticas com o vídeo inúmeros recursos de edição e montagem - como cortes, sobreposições, distorções, anamorfoses, mosaicos, colagens, colorizações, compressão ou expansão da imagem (squeezoom) - que tornaram possíveis a expansão e a hibridização da linguagem videográfica ${ }^{10}$.

No que diz respeito à intertextualidade, o vídeo Marca Registrada pode ser relacionado a diferentes textos visuais, tais como pinturas, fotografias, assemblages e outros vídeos produzidos na mesma época, mas, também, com obras que surgiram após o ano de 1975, que podem ser consideradas reverberações do vídeo Marca Registrada.

Nos anos 1970, a artista Gina Pane ficou conhecida por suas "ações”, como em Ação Sentimental (1973), (Fig. 5 e 6), marcada por comportamentos violentos e agressivos sobre o próprio corpo.

Nessas ações, a artista se cortava, produzia sinais sobre o corpo e introduzia objetos na pele dos braços, tórax e outras partes do corpo.

Para Gina Pane, o termo perfomance era excessivamente teatral, e sua proposta não era encenar por meio do corpo, mas tornar o seu corpo a própria linguagem artística; era uma questão política. Por isso, suas intervenções eram realizadas ao vivo e sobre a materialidade do corpo, a fim de torná-lo matéria plástica e sensível, engajada politicamente, durante o próprio ato e momento mesmo de produção da obra.

Entre as ações que imprimem grafismos, desenhos ou sinais sobre a pele do corpo, pode-se mencionar um conjunto de obras que exploram o corpo como uma rede de imposições e poderes políticos e culturais, como é o caso de Ação Sentimental, mas, também, do corpo bordado/tecido do vídeo Marca Registrada.

De igual maneira, a ação de amarrar o próprio rosto com um fio de nylon e o ato de costurar a boca da fotografia de si mesmo, impressa num delicado tecido branco preso a um bastidor, remetem a posturas críticas e denunciativas da condição social e política do corpo feminino. Trata-se da obra em vídeo Sem Titulo (1977), de Sônia Andrade, e do bordado sobre xerox Sem Título (1997), produzido vinte anos depois, de Rosana Paulino (Fig. 06 e 07).

$\mathrm{Na}$ análise da intertextualidade, ambas as obras dialogam com Marca Registrada, pois projetam seus textos na confluência dos corpos

\section{REGILENE RIBEIRO}

Diálogos estéticos e alguns caminhos da intertextualidade para história da arte e do vídeo

10. MACHADO, A. A arte do vídeo.

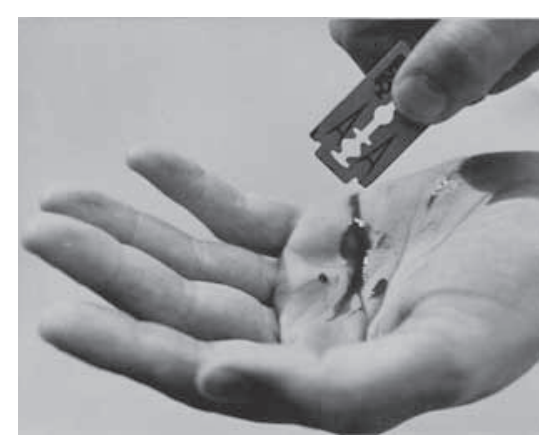

FIGURA 05.

Gina Pane. Ação Sentimental, 1973. Ação realizada na Galeria Diagrama, em Milão, Itália. Fotografia colorida. $120 \times 100 \mathrm{~cm}$. 

presente nas obras por meio da linha/cordão resistente que amarra e

FIGURA 06.

Sônia Andrade. Frame do vídeo s/título, 1977. Vídeo P\&B, 04 minutos. Made in Brasil.

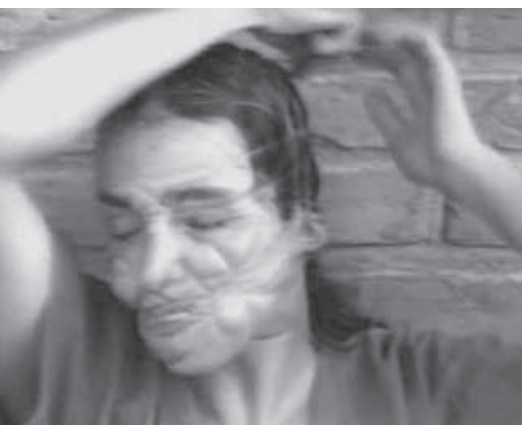

FIGURA 07.

Rosana Paulino.

Sem Título, 1997.

Xerox sobre tecido e costura montado em bastidor. $30 \mathrm{~cm}$ de diâmetro. Acervo do MAM SP.

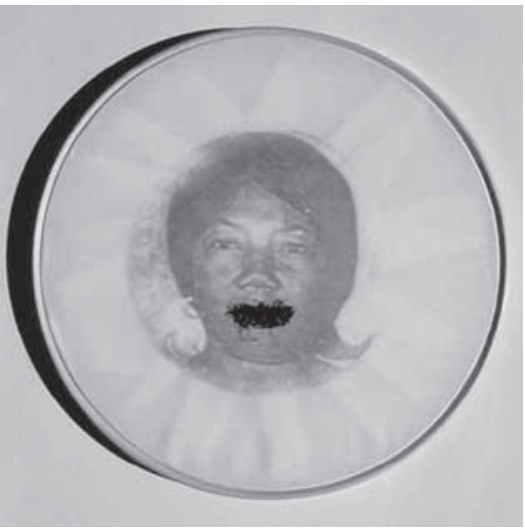

deforma o rosto feminino de Sônia Andrade, ao mesmo tempo em que borda e veda a boca de Rosana Paulino, cerrando seus lábios e sua capacidade de falar com o mundo. As referidas obras discorrem sobre o corpo e sua condição feminina, política e cultural.

Em Marca Registrada, uma mulher carrega sobre a sola dos pés uma marca, que, embora escondida debaixo de seus pés, o corpo sabe possuir, sentindo que tal registro determina seu pertencer coletivo e social, porque o compartilhar do ato de bordar tornou o corpo um sujeito extrovertido. Na obra Sem Título de Sônia Andrade, uma mulher marca seu rosto e o exibe alterado na condição idealizada, cujo ato sufocante aprisiona a mente e o corpo. $\mathrm{O}$ rosto é alterado em sua beleza para revelar o desconforto de ser modelado, amarrado e pressionado socialmente. Por fim, na de Rosana Paulino, há uma mulher que, por saber que está diante da sociedade, do racismo e do machismo, exibe sua marca política: o não poder se expressar e o calar diário, torturante, que se impõem sobre seu corpo.

Outras duas referências podem ser relacionadas, no campo da intertextualidade, ao vídeo Marca Registrada. Trata-se das bordaduras de José Leonilson e da obra sobre tecido de Domingos Mazilli (Fig. 8 e 9).

Além das relações políticas e culturais, o tom irônico e a relação direta para com as pequenas políticas de controle cercam a temática do corpo na obra dos referidos artistas. Eles denunciam o cerceamento da liberdade e o condicionamento dos comportamentos humanos. É o caso da complexa obra Homem vazio (1991), de Leonilson. Nela, o artista se apropria de linhas e tecidos para narrar sua vida pessoal, tecer o corpo na obra, dando ênfase às relações com a mãe e à discussão dos papéis impostos social e sexualmente ao corpo masculino.

De outra forma, o corpo de Marca registrada encontra-se na mulher presente na obra Regras, de Mazzini. Os sinais se fazem visíveis na contrariedade do bordado e das manchas coloridas de vermelho e cor de pele, das frases do delicado tecido para anáguas marcado/tingido pelo sangue das regras menstruais femininas, que extirpam para fora do corpo o que não se configurou em vida.

Nesse contexto, cabe ressaltar a importância do diálogo e das aproximações entre os diferentes textos por meio da intertextualidade, 


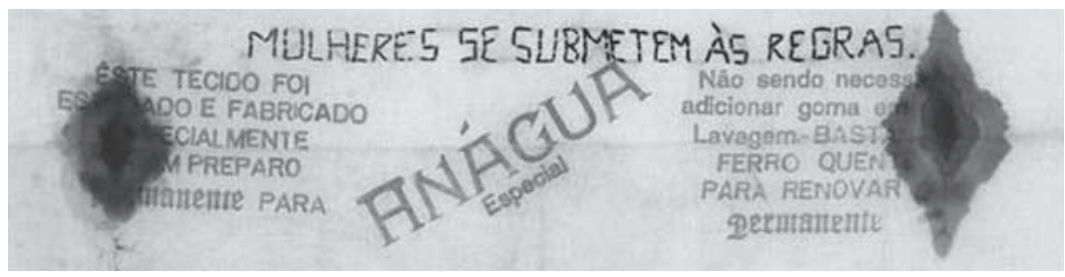

acrescentando às análises contribuições estéticas e comparações que podem revelar os diferentes modos de presença do corpo como operador de sentido na comunicação e na arte, como destaca Bracchi:

Os atores da enunciação posicionados em um tempo e espaço do discurso se mostram por seus comportamentos e movimentações estésicas, somáticas e intersomáticas que eles processam a partir das marcas do seu sentir materializadas no plano da expressão. Além das relações de intertextualidade, os procedimentos discursivos e sua manifestação permitem ao analista reunir relações comuns estabelecidas entre grandezas dadas na interdiscursividade. Assim é que se reconstroem os modos de presença do ator da enunciação e de seu corpo colocado na enunciação ${ }^{11}$.

Da intertextualidade revelada pelo diálogo estético de Marca Registrada com outros textos visuais depreende-se um conjunto de competências de ordem estética, temática e figurativa, como aspectos políticos, culturais, sociais e sinestésicos compartilhados pelo artista e pelo público na construção de sentido. O diálogo com outros textos - músicas, imagens, desenhos e pinturas - participa da construção de sentido e as referências podem aparecer direta ou indiretamente na plástica dos vídeos.

A primeira obra a se comentar como intertexto presente no vídeo Entre é a pintura A origem do Mundo (1866), de Gustave Courbet (Fig. 10). Convém citar um estudo fotográfico contemporâneo, que se refere à pintura de Courbet, realizado pelo fotógrafo Auguste Belloc: Photographies obscènes pour stéréoscope, de 1860 (Fig. 11).

Note-se que a semelhança da posição da mulher, de pernas abertas, exibindo seu órgão sexual de frente para a câmera fotográfica, e o cromatismo da pele e do vestido que compõem a cena podem ser relacionados à pintura de Courbet e ao vídeo Entre. Em A Origem do Mundo, Courbet revela músculos, dobras e a anatomia de um corpo nu feminino que exala sexualidade, tornado a matriz feminina que dá continuida-

\section{REGILENE RIBEIRO}

Diálogos estéticos e alguns caminhos da intertextualidade para história da arte e do vídeo

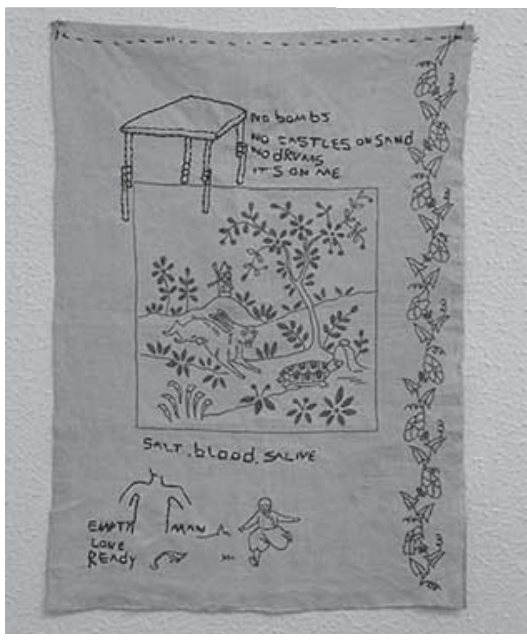

FIGURA 08.

José Leonilson. Homem vazio, 1991. Bordado sobre linho. 54 x 39 cm. Coleção Família Bezerra Dias, São Paulo.

FIGURA 09.

Domingos Mazilli. Regras, 2007. Bordado, impressão e pintura sobre seda. Coleção do Artista.

FIGURA 10.

Gustave Courbet. L'origine du monde, 1866. Óleo sobre tela. $46 \times 56 \mathrm{~cm}$. Museu D'Orsay. Paris.

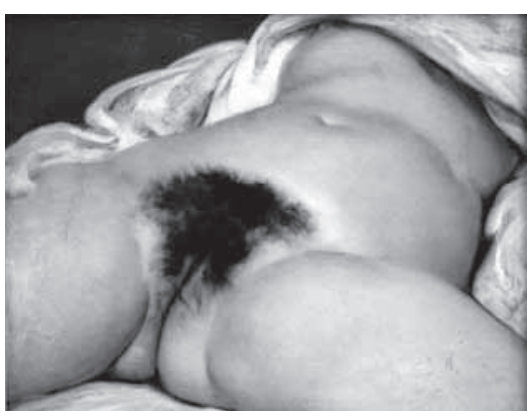


Étant Donnés é uma das últimas obras produzidas por Duchamp. Em 1968, após a morte do artista, o Museu de Arte da Filadélfia montou o projeto de instalação encontrado entre os escritos o artista. A referida obra é uma instalação na qual o público assume a postura de voyeur; espreitando pela fresta de uma porta, vê-se uma mulher deitada, um manequim tridimensional, com o sexo exposto; mas não se vê seu rosto.

A intertextualidade observada entre a obra de Duchamp e o vídeo Entre pode ser descrita pelas posições do corpo feminino, que, em ambas, é figurativizado de pernas abertas. Cabe notar que na obra do mestre dadaísta as pernas femininas se encontram voltadas para o público, que se coloca a olhar pelo orifício disposto no centro da porta que o separa daquele corpo para desvendar os mistérios da obra.

Nesse trabalho, o público entra por meio da pequena abertura feita na porta, que permite quem está de fora olhar para dentro e lá encontrar-se com o corpo feminino. Já no vídeo Entre, o público entra na obra por meio do outro masculino, de outro corpo, por meio da tela do vídeo, que lá dentro já está e que se encontra entre as pernas, de frente para o corpo feminino, embora de costas para o público.

As duas obras são contrárias nesse sentido, mas ambas tratam de acessos ao corpo feminino e de espaços entre o corpo feminino e o corpo masculino. Ambas discutem o corpo feminino e o corpo masculino, e a posição contrária das pernas femininas - em uma obra de frente e na outra de costas para o público - não impede que se saiba ser ali o local de encontro com a sexualidade feminina e masculina. Daí o fato do artista do vídeo Entre posicionar-se de costas para o público; ele gera mais atração no público, que por contágio se vê regido pelo desejo incontrolável de adentrar o corpo da mulher, mesmo que este permaneça velado, escondido dentro do vídeo. Justifica-se a relação intertextual proposta, porque se percebem relações no enquadramento em close-up das pernas brancas femininas, do órgão sexual feminino entre as pernas e dos pelos escuros à mostra.

Entre os anos de 1973 e 1977, Friederike Pezold produziu uma série de vídeos denominados A nova encarnação da linguagem dos sinais de um sexo segundo as leis da anatomia, geometria e cinética. O vídeo é composto de imagens em movimento, as quais, durante 10 minutos, apresentam um corpo feminino em partes cobertas por uma pintura preta. Conforme relata Fricke: "Numa sequência não editada de grandes planos, seios, braços, olhos, coxas e órgãos genitais têm vida própria altamen-

\section{REGILENE RIBEIRO}

Diálogos estéticos e alguns caminhos da intertextualidade para história da arte e do vídeo

FIGURA 12.

Still do vídeo Entre (Nina Galanternick.1999, 06'. Colorido).

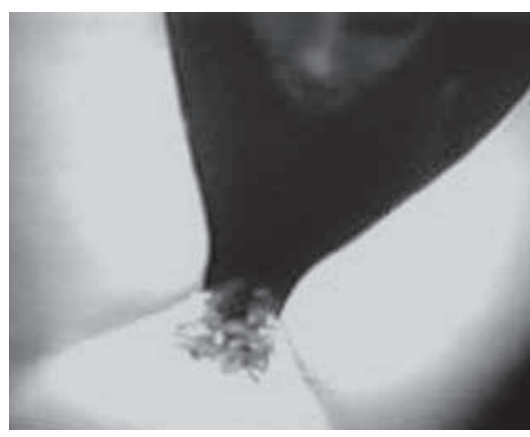


ARS te estilizada, o que, por sua vez, abre um vasto leque de associações"12. ano 12 A intertextualidade entre o vídeo Entre e este vídeo de Pezold pode ser n. 23 evidenciada pela plástica do corpo, pelos enquadramentos e zooms que, somados aos detalhes da tinta preta, definem os membros femininos. As obras se aproximam na forma, nos contornos, no cromatismo das cenas e no conteúdo erótico e sensual, tematizado em ambos os vídeos.

$\mathrm{Na}$ atualidade, destaca-se a intertextualidade do vídeo Entre por meio de diálogos com a obra Vulvas Metálicas (1998), de Franklin

12. FRICKE, C. Novos Media. In: WALTER, Ingo F. (ed.). Arte do Século XX - vol II
Cassaro, e A origem do terceiro mundo (2010), do artista Henrique de Oliveira (Fig. 14 e 15).

Franklin Cassaro, em sua Coleção de Vulvas metálicas, utiliza 180 peças de alumínio e metal, feitas com tampas de latinhas, potes e panelas; com um gesto sintético e uma única operação de dobrar o material, ele

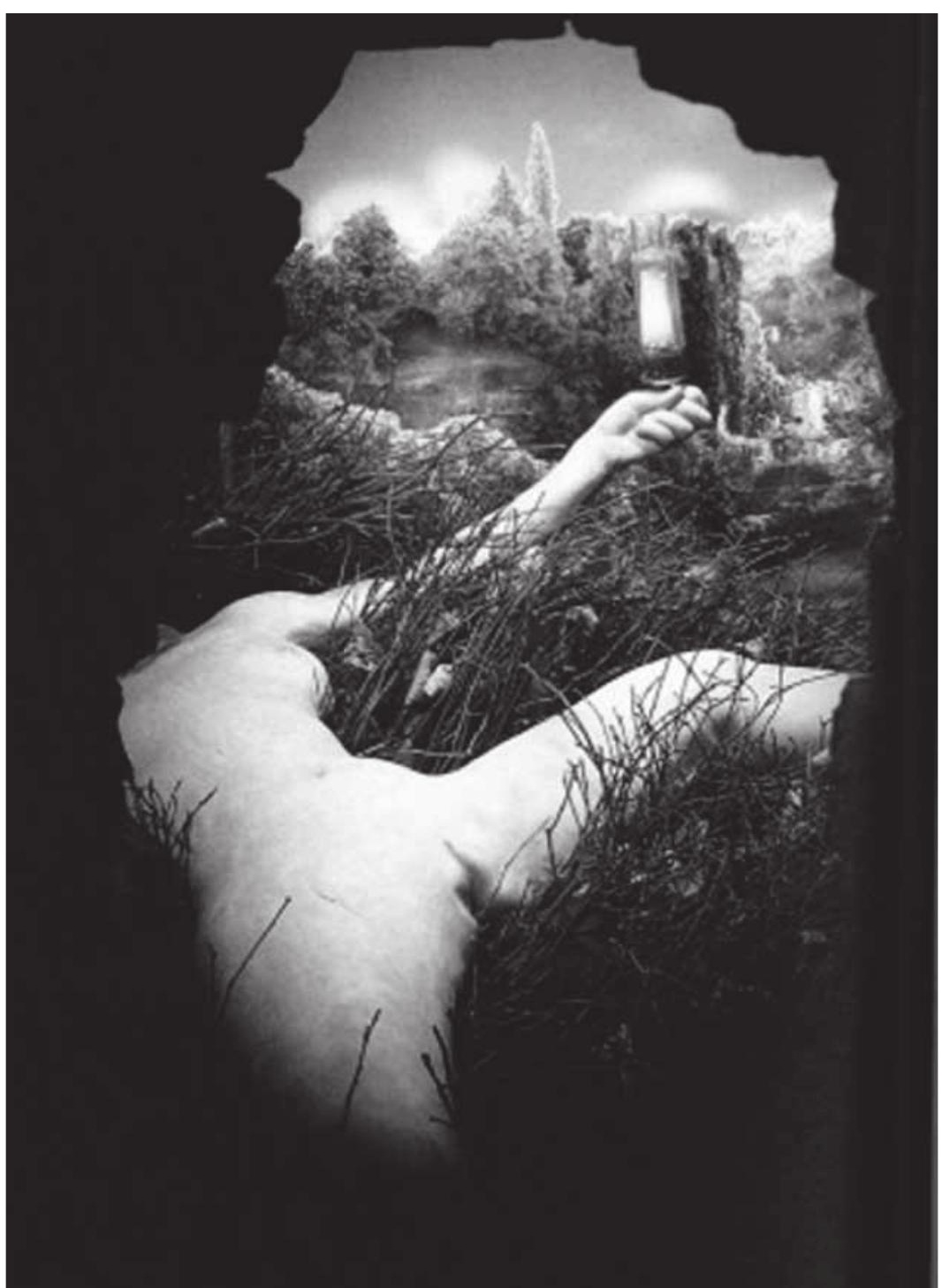


dá forma ao órgão sexual feminino. Essas pequenas esculturas, expostas juntas e ao mesmo tempo, exercem um fascínio que atrai o público pela forma acolhedora do órgão, figurativizado em vários recipientes ovalados.

Cabe notar que o gesto desse artista perverte totalmente a função original das tampas, que consiste em fechar e vedar invólucros. $\mathrm{Na}$ coleção de Cassaro, as tampinhas são formas receptivas e abertas, que se traduzem em caminhos, trajetos que convidam a adentrar os corpos, e, assim como no vídeo Entre, oferecem inúmeras possibilidades de se alcançar o desejo e o prazer.

Por sua vez, o artista Henrique Oliveira apresentou, na 29 ${ }^{\text {. Bie- }}$ nal de São Paulo, em 2010, uma obra que dialoga diretamente com o vídeo Entre. Embora se trate de uma instalação, ocupando uma espacialidade tridimensional, e tenha uma materialidade totalmente distinta, a temática se relaciona com a origem do mundo, com o nascimento e a sexualidade, como o próprio título indica: A Origem do Terceiro Mundo.

Por um lado, a instalação dialoga com aspectos políticos e culturais - ela é feita com madeira de tapumes de construções civis, recolhidas pelo artista nas ruas, usadas também na construção de casebres e favelas, fala sobre o cotidiano das grandes cidades e da vida nas periferias e do espaço urbano, relacionados aos países do denominado terceiro mundo.

Por outro lado, dialoga com o adentrar o corpo feminino. A instalação é uma grande caverna de madeira, uma vagina gigante, dentro da qual se pode penetrar e caminhar pelos canais que figurativizam um útero feminino. As madeiras alaranjadas, amareladas e em tons de rosa e vermelho, somadas às formas arredondadas e orgânicas, dão materialidade à carne e ao interior do corpo feminino, cujos canais ou passagens revelam texturas e nervuras do útero, onde todo nascimento começa.

Visto por dentro, esse corpo feminino, que nutre a vida, relaciona-se com os corpos do vídeo Entre, com as Vulvas Metálicas e com a Origem da Vida de Courbet, que exibem o acesso ao portal que leva ao corpo interior: a vagina. Trata-se, aqui, de um estar dentro do corpo e, depois, de um momento posterior ao ato sexual, libidinoso, cujo desejo e prazer de penetrar e se encontrar com o outro resvala no nascimento de outros corpos.

Visando a uma análise da intertextualidade no vídeo Narciso (2001), de Danillo Barata, ressaltam-se relações entre o trabalho e o mito da figura masculina que se apaixona por si mesma, figurativizada em diferentes obras artísticas e em épocas distintas. É possível partir do mito de Narciso figurativizado nas pinturas de Michelangelo Meresi

\section{REGILENE RIBEIRO}

Diálogos estéticos e alguns caminhos da intertextualidade para história da arte e do vídeo

\section{FIGURA 14.}

Franklin Cassaro. Vulvas metálicas, 1998. Corpos Subterrâneos - Itaú Cultural.

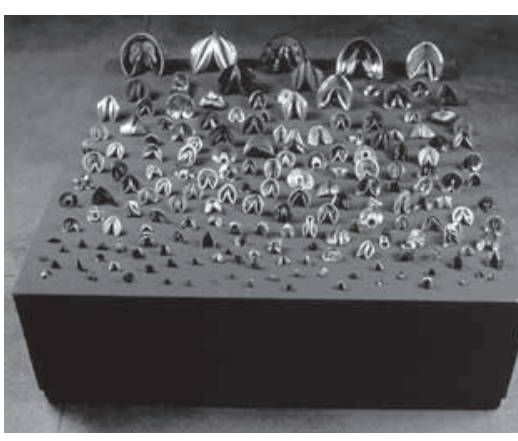

FIGURA 15.

Henrique Oliveira. A Origem do Terceiro Mundo, 2010. Madeira, PVC e metal. 4,9 × $45 \times 5$ m. 29 a Bienal de São Paulo.

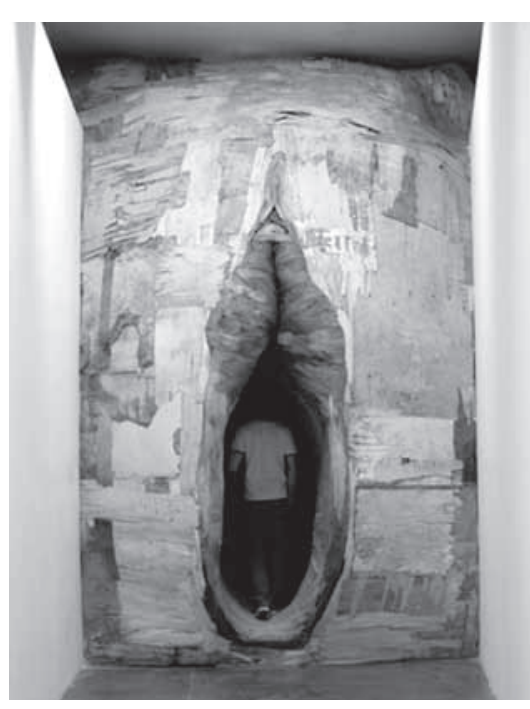


ARS da Caravaggio, passando por obras de Nicolas Poussin, John William ano 12 Waterhouse e Karl Brulloff, chegando até o narciso moderno de n. 23 Salvador Dali.

Cabe notar que, em todas as obras destacadas, o corpo de Narciso aparece debruçado sobre sua própria imagem, de frente para o público, reiterando o convite a que o público se projete sobre o corpo figurado, impondo sua beleza do alto, para se ver e se encontrar consigo mesmo, seja na pintura, na fotografia ou no vídeo. Em algumas representações, o corpo de Narciso, é masculino, esbelto, musculoso; em outras, é figurativizado lânguido, preguiçoso, tomado e contaminado totalmente pelo vislumbre do encontro consigo mesmo; em outras, ainda, Narciso é imponente, enérgico e dissimulado.

A investigação de textos revela referências significativas para a análise do tema do Narciso na atualidade. A célebre instalação da artista japonesa Yayoi Kusama, as obras em reprografia de Hudinilson Junior e as fotografias de Lourdes Colombo, por exemplo, realizadas mais recentemente, retomam o mito. Essas obras discutem os papéis sociais do corpo feminino e tratam das novas formas de conhecimento do corpo por meio das tecnologias da imagem e do som.

O primeiro texto referenciado é a pintura Narciso, de Caravaggio (Fig. 16). A mais antiga das pinturas aqui tratadas, de 1597, parece também ser a obra que mais se aproxima do vídeo Narciso de Danillo Barata, porque apresenta somente a figura masculina de Narciso. De igual forma, a obra Narcissus (1819), de Karl Bruloff (Fig. 17), pode ser citada como exemplo de pintura sobre o mito de Narciso que não traz Eco, a figura feminina do mito - a outra figura que aparece na obra é a do anjo/cupido.

Cabe ressaltar, ainda que brevemente, uma oposição entre as duas pinturas: se Caravaggio cobre o corpo do rapaz, ressaltando seu reflexo envelhecido, Bruloff despe Narciso e o apresenta como um deus grego, eternamente jovem. O Narciso de Caravaggio se reconhece em seu envelhecimento; o de Bruloff se identifica com sua imagem eternamente jovem.

Os contextos dessas obras revelam os traços estilísticos que retratam os papéis sociais do corpo masculino do Século XVI que permitiam a Caravaggio representar Narciso como um sujeito perturbado e, ao mesmo tempo, hipnotizado pela dramaticidade e expressividade do homem quinhentista, que se via refletido envelhecido. Ao passo que, na pintura de Bruloff, é figurativizado um Narciso que reitera a beleza 


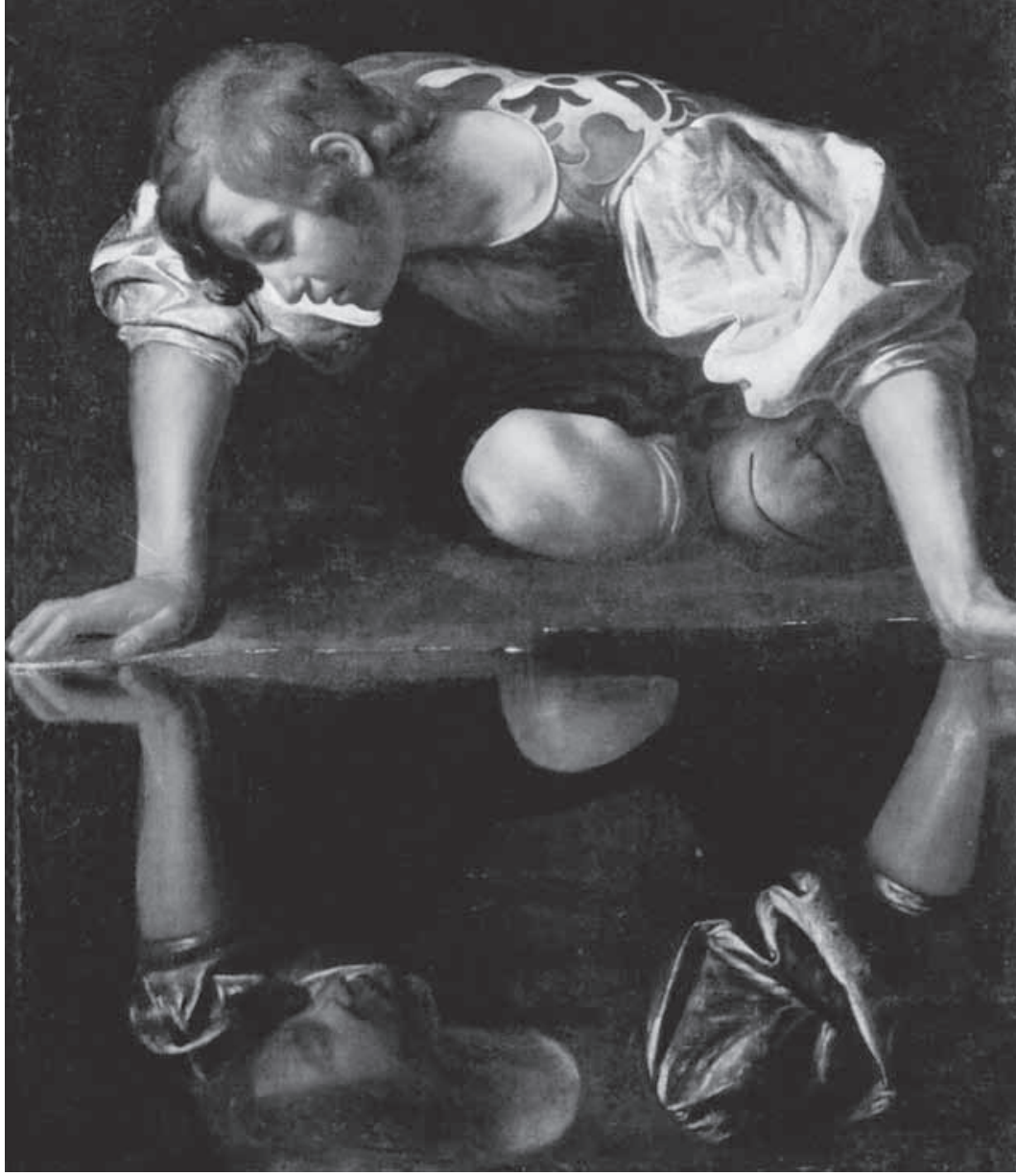

greco-romana em seus traços figurativos, corpo másculo, nu, vestindo sandálias romanas, presentificado numa época de retomada dos valores clássicos (era o neoclassicismo do Século XIX).

Retomando a análise de Narciso de Caravaggio, trata-se de um corpo debruçado na beira de um lago, um corpo jovem vestindo os trajes da época - camisa branca de mangas longas e exuberantes, calça verde pelas canelas e colete em tons de marrom, com desenhos de formas orgânicas nas costas. O cabelo castanho dourado está penteado, e as longas franjas caem sobre a testa pelo lado direito do corpo, próximo ao braço que sustenta seu peso.

Na paisagem que compõe a cena da pintura e seu entorno, observa-se uma pequena faixa de terra, levemente avermelhada em tons de marrom, e a água, que reflete Narciso; não se sabe se é um lago ou uma pequena poça. O que se vê claramente é o reflexo de uma pessoa: um homem mais velho do que o garoto que ali se debruça. O corpo e seu reflexo estão espelhados no sentido horizontal, em uma composição simétrica, no formato de um círculo que compreende o espaço topológico da tela.

\section{REGILENE RIBEIRO}

Diálogos estéticos e alguns caminhos da intertextualidade para história da arte e do vídeo

FIGURA 16.

Michelangelo Caravaggio. Narciso, c.1597. Óleo sobre tela. $100 \times 92 \mathrm{~cm}$. Galeria Nacional de Arte Antiga. Palazzo Barberini, Roma.

\section{FIGURA 17.}

Karl Brulloff. Narcissus, 1819. Óleo sobre tela. $162 \times 219 \mathrm{~cm}$. The Russian Museum,

St. Petersburg.

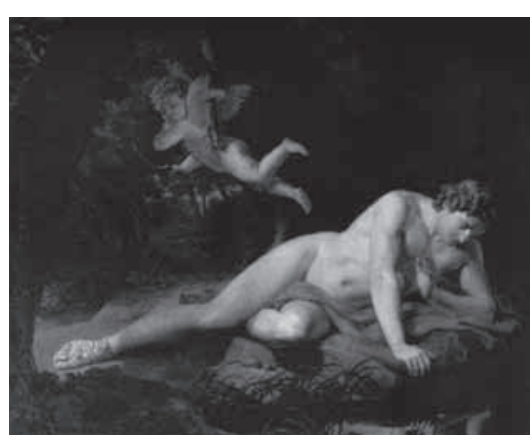


O Narciso que se exibe na pintura está a mostrar-se para si

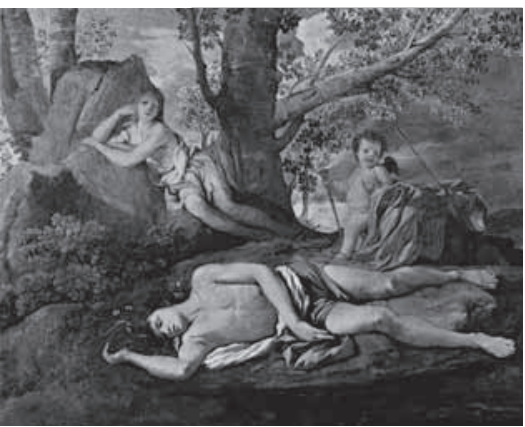

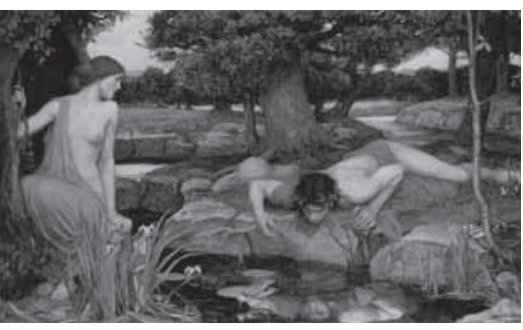

FIGURA 18.

Nicolas Poussin. Eco e Narciso, 1630. Óleo sobre tela. $74 \times 100 \mathrm{~cm}$. Louvre, Paris.

FIGURA 19. John William Waterhouse. Eco e Narciso, 1903. Óleo sobre tela. 109,2 2 189,2 cm. Liverpool, Walker Art Gallery. mesmo, em toda sua dramaticidade, mas é por meio daquele outro corpo refletido na poça d'água que este se sente presente. Narciso se reconhece naquele corpo ausente, que se presentifica por meio do reflexo de si mesmo. Isso também ocorre no vídeo Narciso, de Danillo Barata, na medida em que corpos se exibem e se deixam ver como voyeurs. Esses corpos se escondem, velando-se e se exibindo em fragmentos e coloridos, buscando identificar-se a si mesmos por meio do corpo do outro, conquistando assim sua identidade própria.

Do pintor Nicolas Poussin, Narciso aparece na obra Eco e Narciso (1630), também conhecida como A morte de Narciso (Fig. 18). Na referida pintura, Narciso está em primeiro plano expondo-se em sua beleza carnal; corpo belo e jovem, diante do público, mas corpo sem forças perante o amor implacável que sente por si mesmo. Eco, a figura feminina da ninfa, bela jovem que despreza o amor, aparece mais ao fundo da tela, comodamente encostada em uma pedra, observando impávida e sem ânimo o fim de Narciso. A composição dos dois corpos, Eco e Narciso, confere uma triangulação à topologia pictórica que se projeta na figura do anjo - ou na figurativização de um cupido, metáfora do amor esperançoso de Nicolas Poussin. Na pintura, contracenam a vida e a morte por meio de Narciso, que tematiza o corpo apaixonado e ensimesmado ante a presença do outro.

Tanto o corpo feminino, Eco, quanto o corpo masculino, Narciso, operam o destino implacável e trágico do discurso mítico de Ovídio em Metamorfoses.

Na obra Eco e Narciso (1903), de John William Waterhouse (Fig. 19), a figura de Eco está à frente de Narciso e o encara como se discordasse de sua paixão descomedida para consigo mesmo. Eco veste uma túnica rosa envelhecida e exibe seus seios delicados e jovens, enquanto Narciso se debruça sobre o lago com o corpo coberto por uma veste vermelha, trazendo um ornamento de louros verdes sobre a cabeça, o que o torna belo e gracioso. Narciso não vê Eco do outro lado do lago; seu reflexo na água é demasiado atraente.

O Narciso (1937) de Salvador Dali (Fig. 20) é representado pela flor de nome Narciso, que brota de um ovo no alto e à direita da tela, em meio às rochas e pedras antropomorfizadas do artista. $\mathrm{O}$ ovo, símbolo da fertilidade e do renascimento, é delicadamente segurado por uma mão, cujos dedos finos e esguios, em tons pálidos de azuis e verdes, 
elevam-se até próximo ao céu, e, no alto, vê-se brotar o narciso: pétalas brancas, miolo amarelo, folhas e caules verdes que venceram a casca do ovo e vieram ao mundo.

À esquerda do totem há um conjunto de rochas em tom alaranjado, cuja forma de homem sentado com a cabeça abaixada e encostada sobre o joelho esquerdo tematiza um ser pensante. A seu lado, outro totem, de cor cinza azulada, presentifica-se como um espelho do ser pensante. Abaixo, na altura dos pés desse corpo viril e musculoso, há uma forma ovalada, um pequeno lago que reflete a figura dourada até a altura de suas pernas. Nesse reflexo, não se vê a cabeça do homem; seu corpo é refletido incompleto.

Cabe ressaltar que a figura da rocha tem o mesmo tamanho, altura e forma da mão, de modo que ela configura um conjunto simétrico entre o ovo e cabeça, entre as pernas e os dedos, como pilares que sustentam narciso-flor e narciso-corpo. O corpo do público, ao interagir com essa pintura, irá interagir com a presença edificada da flor e do corpo, que se projetam e se refletem mutuamente, em diferentes simetrias, para compor a paisagem do pequeno lago, que, por sua vez, reflete a identidade do sujeito moderno, petrificado e exposto em sua materialidade.

O corpo se converte em lugar da criação que nutre os renascimentos. A construção de sentido do mito de Narciso se dá por meio do discurso do corpo figurativizado por dedos finos,magros e azuis pálidos, que presentificam a ausência da vida, em contraposição à presença da vida, que se observa no corpo dourado e laranja, quente, vida pulsante.

O Narciso de Danillo Barata dialoga com esse texto pictórico de Dali, na medida em que representa o mito como um sujeito da modernidade que se percebe refletido em sua condição de vítima do sistema político e social. Estagnado e preso às amarras que o encerram em seu próprio corpo e no corpo prostrado em pensamento diante do reflexo incompleto de si mesmo. Frente ao sentimento de alteridade que a realidade reserva a ele, não lhe cabe outra coisa senão exibir-se e velar-se, na esperança de reconhecimento de si mesmo e de conquistar sua identidade narcisista.

Dentre os textos encontrados para o exercício da intertextualidade, convém evidenciar duas obras, de artistas mulheres, que figurativizam o tema do Narciso de forma diversa. Na série Reflexos (1987), de Lourdes Colombo (Fig. 21), um conjunto apresenta a artista observando-se na frente de um espelho. A artista olha para si mesma de maneira tão intensa e curiosa, absorvida pela imagem da mulher que vê diante de si, que

\section{REGILENE RIBEIRO}

Diálogos estéticos e alguns caminhos da intertextualidade para história da arte e do vídeo

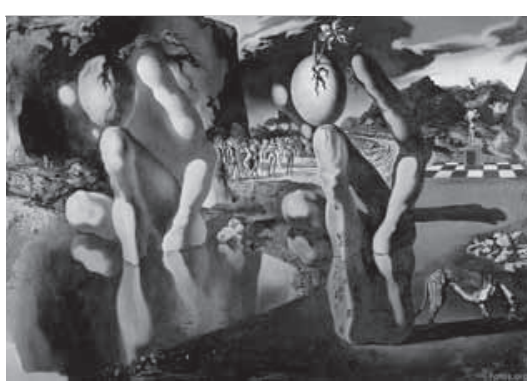

FIGURA 20.

Salvador Dali. Metamorfose de Narciso, 1937. Óleo sobre tela. $50,8 \times 78,3 \mathrm{~cm}$.

Tate Modern, London. 
as fotografias acabam por revelar sua atitude enamorada e ensimesmada perante sua própria imagem. "Repare na maneira como ela se olha, a expressão lânguida de suas mãos, o olhar atento e fixo no espelho (...)"13.

A instalação Jardim de Narciso (2009), da artista Yayoi Kusama (Fig. 22), é uma interpretação intrigante do mito. A obra coloca o público dentro de si mesma, para que o público ele mesmo se torne o corpo de narciso, visto por meio do seu próprio reflexo dentro da obra.

13. CANTON, K. Espelho do Artista [auto-retrato]

FIGURA 21. Lourdes Colombo. Série Reflexos, 1987. Fotografias. Coleção da artista.

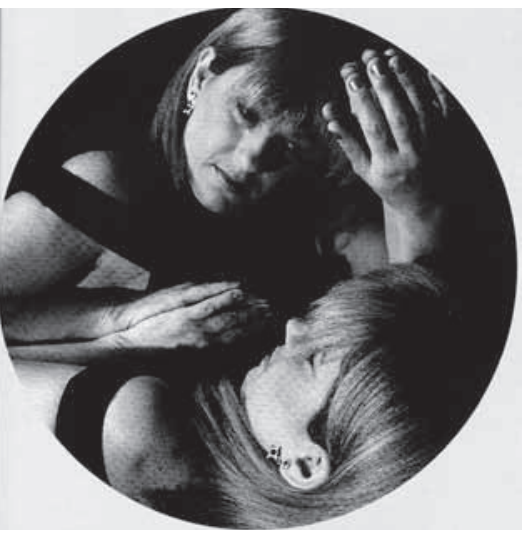

FIGURA 22.

Yayoi Kusama. Jardim de Narciso, 2009 (detalhe). Instituto Inhotim, Minas Gerais.

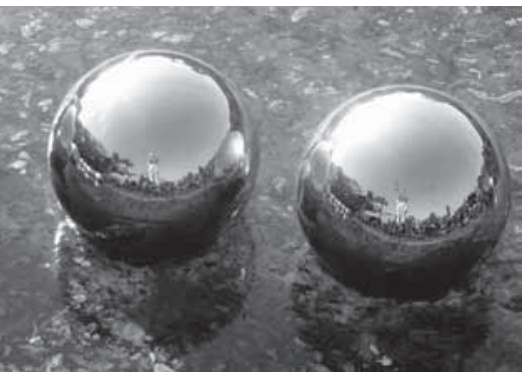

O Jardim de Narciso foi realizado em outra versão, menos paisagística, em 1966. Na versão de 2009, a artista compôs uma instalação sobre um lago com quinhentas bolas de aço inoxidável, que espelham a natureza ao redor e se movimentam com o vento. Nessa versão da obra, não há um corpo que realize uma performance olhando para si mesmo, mas somente os reflexos do entorno revelados meio das esferas metálicas reluzentes. Narciso é a natureza e, ao mesmo tempo, pode ser um transeunte curioso, que se tornará um público participante da obra; ao conhecer a obra, acabará por nela se reconhecer.

Nessa obra, o que se tem é a presentificação do mito de Narciso sem a presença de um corpo humano tradicional, pois não há a figurativização de nenhum corpo específico, feminino ou masculino; há apenas corpos refletidos e presentes nas esferas. As esferas atuam como espelhos que refletem aqueles que olham para si mesmos e que, deslumbrados, reconhecem-se em um corpo.

Ainda que não fique claro de imediato que aquela obra tem como tema o mito, a interação com o jardim de esferas de aço levará o público ao contágio, através da materialidade da obra. A reflexividade o fará vivenciar a experiência de se ver refletido pelo discurso mítico do Jardim de Narciso. A obra conversa com o vídeo de Danilo Barata na medida em que ambas buscam a construção da identidade do sujeito, interpretando o mito. Ambas atuam por meio da materialidade, seja por meio da materialidade reflexiva das esferas em Jardim de Narciso, seja pelo espelhamento causado pelas imagens videográficas do vídeo Narciso, que levam o sujeito/público ao encontro consigo mesmo.

Cabe ressaltar que no vídeo o corpo é velado por filtros coloridos e pelo enquadramento fechado, que não permite que o corpo se veja por inteiro. $\mathrm{O}$ artista é um corpo visível porém velado pela interação com o vídeo. Da mesma forma, na instalação, o reflexo do público é velado e só será visível quando ele se aproximar do lago de esferas e se debruçar sobre seu leito, apenas lá dentro da obra podendo encontrar- 
-se com seu pequenino reflexo. Este reflexo, por sua vez, se reunirá novamente à coletividade das esfera ao mais leve movimento das águas, que faz a imagem de Narciso se perder.

Para dialogar com a obra Desenho-corpo (2002), de Lia Chaia, têm-se as referências que se alimentam da ancestralidade de povos e raças humanas e que reiteram hábitos culturais, como desenhar, pintar e adornar o corpo para rituais oferecidos às atividades cotidianas e religiosas (Fig. 23). Na sequência, foi estabelecido um diálogo entre Desenho-corpo e a obra contemporânea de Marcela Tiboni (Fig. 24).

Sabe-se que os rituais imprimem no corpo preparações e transformações que visam a atender às divindades que coordenam atividades naturais como a chuva, a colheita, a caça e festejam a vida, o nascimento e a morte. Ou, ainda, divindades que são convocadas em ritos de passagem, como nos rituais realizados com adolescentes que irão se tornar adultos, ou que estão prestes a passar por um renascimento para a vida adulta, e assim por diante. Essas práticas, realizadas ainda hoje por autóctones, aborígines, indígenas e povos nativos de diferentes raças, sustentam-se por meio de tradições culturais que se remetem às comunidades existentes antes da constituição das grandes civilizações tecnológicas, persistindo na continuidade de seus rituais e tendo como uma das forças presentes a pintura corporal.

Uma vez que o objetivo não é um estudo aprofundado dessas imagens, nem sua descrição antropológica, cabe ressaltar de forma breve a similaridade e a proximidade estética entre as pinturas corporais e o vídeo Desenho-corpo. Isso é observado nas fotografias de pintura corporal das tribos Assurini e Kadiwéu e nas fotografias de Claudia Andujar, que flagram diferentes rituais de adornos corporais, que se dão por meio da introdução de objetos, tatuagens e pinturas repletas de simbolismos que preparam os corpos para as práticas culturais indígenas.

Mais recentemente, e dentro do cenário das artes visuais como no vídeo Desenho-Corpo, encontram-se os trabalhos conceituais de Marcela Tiboni. Conforme afirma Kátia Canton, na arte contemporânea o corpo é a materialidade da arte, algo muito além do conceito de suporte:

Artistas modernos já utilizaram o corpo como moldura para a produção contemporânea. Yves Klein, por exemplo, tornou-se célebre por suas conhecidas Antropometrias, em que os corpos nus de suas modelos eram pintados com a tonalidade azul profundo (que ficou

\section{REGILENE RIBEIRO}

Diálogos estéticos e alguns caminhos da intertextualidade para história da arte e do vídeo

\section{FIGURA 23.}

Claudia Andujar. s/título, 1976. Fotografia. Série Identidade. Índio Yanomami.

Pintura facial e adornos no queixo. Galeria Vermelho.

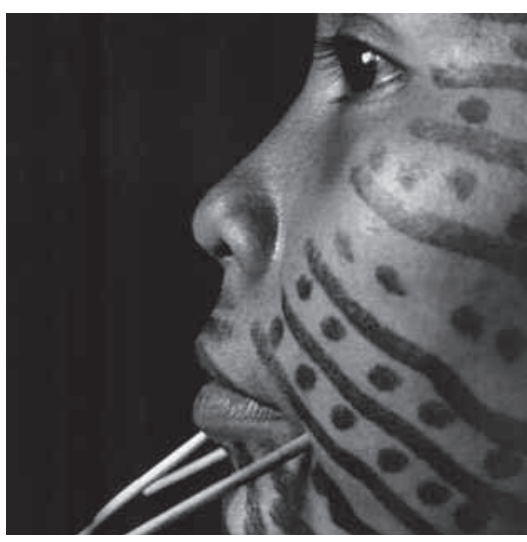

FIGURA 24.

Marcela Tiboni. Estudo para desenho de corpo feminino, 2006. Fotografia. $80 \times 60 \mathrm{~cm}$. Coleção da artista.

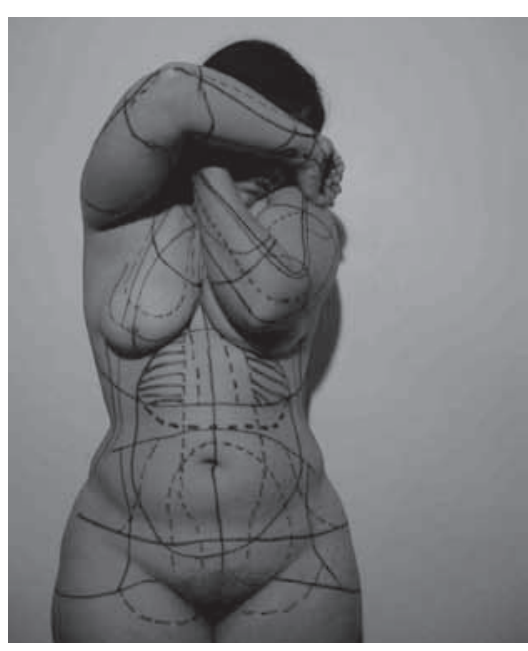


Nas obras Estudo para desenho de corpo feminino (2006), Tiboni registra em fotografias seu corpo desenhado, mas a obra é o seu próprio corpo coberto por tais desenhos. Esses desenhos são semelhantes àqueles que demarcam as linhas de proporções e simetrias que garantem uma composição harmoniosa quando se está aprendendo a desenhar um corpo humano; ou, ainda, àquelas marcações feitas no corpo por cirurgiões plásticos, antes de realizar suas intervenções cirúrgicas. Desenhos negros e tracejados que trilham os caminhos da reconstrução idealista de novas modelagens para aquele corpo, tanto na arte quanto na medicina. Cabe notar que o corpo desenho de Tiboni tem vergonha de si mesmo e se esquiva de olhar para a câmera, cobre seu rosto com os braços e as mãos, vira a cabeça, esconde seus órgãos sexuais, sua intimidade. Mas, ao mesmo tempo, se oferece ao olhar na intimidade das partes de seu corpo, no desenho dos seios, nos traços que revelam os cortes e os músculos de um corpo redesenhado.

A obra se faz na fisicalidade do corpo, e o corpo se mistura ao desenho e à fotografia para se tornar obra. É nessa particularidade que se entende a intertextualidade entre o vídeo de Lia Chaia e a obra de Marcela Tiboni. Em Desenho-corpo, o desenho é o próprio corpo da artista, cujo gesto de desenhar se mistura à cor, que se mistura ao corpo, assim como na obra Estudo para desenho de corpo feminino.

As fotografias de Marcela Tiboni são registros de performances corporais: enunciados visuais que se realizam na linguagem do corpo que lhes confere materialidade, uma vez que nessas obras o corporal é traduzido em gestual. E não se trata do corpo como suporte; pelo contrário, o corpo é a própria obra e não sua base material.

Dado o exposto, cabe comentar a expressão "corpo artista", cunhada pela pesquisadora das artes do corpo Christine Greiner, que pode ser usada para esclarecer algumas das manifestações do corpo na contemporaneidade, como em Desenho-corpo. Para a pesquisadora, o corpo humano passa constantemente por processos evolutivos por meio 
das mais variadas experiências cotidianas, incluindo a atividade estética. Esses processos são necessários à sobrevivência, e o corpo-artista seria um estado de crise, ou um "desestabilizador de certezas" do corpo, experimentado por meio da atividade artística ou estética:

(...) o corpo artista é aquele em que aquilo que ocorre ocasionalmente como desestabilizador de todos os outros corpos (um acidente, uma perda trágica, uma paixão violenta) vai perdurar. Não porque ganhará permanência nesse estado, o que seria uma impossibilidade, uma vez que sacrificaria sua própria sobrevivência. Mas, dessa experiência, necessariamente arrebatadora, nascem deslocamentos de pensamentos que serão, por sua vez, operadores de outras experiências sucessivas, prontas a desestabilizar outros contextos (corpos e ambientes) mapeados instantaneamente de modo que o risco se tornará inevitavelmente presente. Não à toa, o sexo, a morte, o humor, a violência e todo tipo de emoção estão presentes durante essas experiências artístico-existenciais ${ }^{16}$.

Num salto diacrônico no tempo, encontram-se os desenhos anatômicos de Leonardo da Vinci. Não se trata de discorrer sobre essas obras, mas mencionar o quanto os estudos internos e anatômicos do corpo feitos pelo artista dialogam, neste contexto, com o vídeo Desenho-corpo.

Nos desenhos anatômicos de Leonardo da Vinci (Fig. 25), encontram-se ilustrações científicas utilizadas na medicina, que figurativizam o corpo humano. A comparação dos desenhos ao vídeo se deve à interpretação das linhas avermelhadas, circulares e em tramas, sobre a pele do corpo feminino em Desenho-corpo. Essas linhas se aproximam muito da exposição anatômica da corrente sanguínea desenhada em detalhes e realisticamente por artistas desenhistas no passado, bem como por estampas ilustrativas do campo da medicina no presente.

Note-se que as relações intertextuais entre os desenhos anatômicos de Leonardo Da Vinci, o sistema sanguíneo humano e os corpos polimerizados do Dr. Roy Glover são visualmente consistentes. Roy Glover, professor de anatomia e biologia celular da Universidade de Michigan, mistura arte e ciência para dar visibilidade ao corpo interior, como acontece com as veias do sistema circulatório (Fig. 26), vistas na Exposição "Corpo Humano Real e Fascinante”, de 2007. Como noticiou a imprensa brasileira, na referida exposição, 16 cadáveres humanos e 225

\section{REGILENE RIBEIRO}

Diálogos estéticos e alguns caminhos da intertextualidade para história da arte e do vídeo

FIGURA 25.

Leonardo da Vinci. Estudos de Anatomia. Mulher, 1506.

Galeria Academia, Veneza.

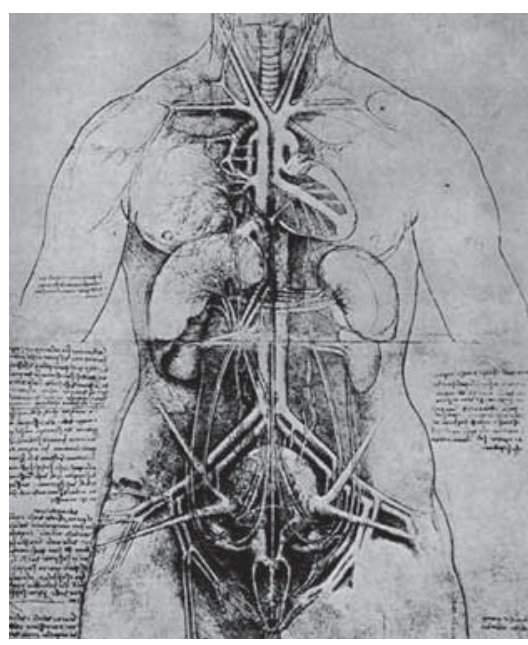

15. GREINER, C. 0 corpo artista como desestabilizador de certezas. In: COCHIARALE, F. e MATESCO, V. (org.) Corpo. São Paulo: Itaú Cultural, 2005 , p. 137-139, p.138. 

tecidos, resultado de um processo denominado polimerização - o processo confere aos órgãos e tecidos uma textura semelhante a do plástico.

O que interessa é a comparação da plástica do corpo interno dos corpos polimerizados com a plástica do corpo externo do vídeo de Lia Chaia (Fig. 27). A comparação é capaz de tecer as relações visuais e simbólicas que se depreendem dessas composições. A primeira resulta da estética de um corpo orgânico que, embora sem vida, tem seu material mantido, preservado, enquanto a plástica da segunda resulta de um discurso sensível, que faz do próprio corpo um simulacro do interno, que deve ser exibido e desenhado para ser visto de fora ou, mais do que isso, para que se possa interagir e se contagiar com o corpo vivo, pulsante, circulante, bem mais preservado que o primeiro, porque é visto vivo.

\section{Considerações Finais}

Ao lançar mão da intertextualidade, o artista seleciona estratégias retóricas as quais acredita serem conhecidas do público; uma vez reconhecidas, tais estratégias podem ser aceitas como parte de um contrato de cumplicidade e confiança entre artista e público. Das estratégias criativas decorre a tarefa do público em compartilhar e construir o sentido por meio de competências para acessar os mecanismos da intertextualidade e se tornar coautor das obras.

Cabe ressaltar que os resultados obtidos pelo exercício de leitura e

FIGURA 26. Sistema Circulatório. Exposição "Corpo Humano Real e Fascinante", 2007. Corpos reais conservados por polimerização. Oca, Parque Ibirapuera, São Paulo.

FIGURA 27.

Frame do vídeo Desenhocorpo. (Lia Chaia, 2002). Linhas traçadas sobre o corpo figurativizam sobre a pele um sistema de veias compostas de sangue.

Artigo recebido em 02 de maio de 2014 e aprovado em 27 de maio de 2014 análise crítica apresentam um panorama singular da arte contemporânea, por meio de aproximações iconográficas realizadas em um conjunto de quatro videoartes e suas relações intertextuais com outras produções artísticas. Como se viu, tendo o objetivo de tecer um diálogo visual por meio do elemento-chave para a compreensão das obras - a intertextualidade -, o resultado apreendido deixa em aberto, para pesquisas futuras, a descrição dos outros intertextos (sons, poesias, palavras) encontrados nas videoartes; os próximos a serem tecidos. Novos caminhos para a história da arte.

Regilene Sarzi Ribeiro é Pós-Doutora em Artes pelo Instituto de Artes da UNESPISP. Doutora em Comunicação e Semiótica pela PUC/SP. Professora Titular e Coordenadora do Curso de Design Gráfico da UNIP/Bauru/SP. Pesquisadora e professora no curso de Artes Visuais da FAAC/UNESP/Bauru/SP. Membro pesquisador da ANPAP. Autora de textos nos livros Corpologias (2014) e Corpo e Cultura (2009). 